\title{
Interrelaciones étnicas establecidas a lo largo de la costa del norte de Chile y sur de Perú en el contexto de la colonia: Los camanchacas ${ }^{1}$
}

Los distintos tipos de relaciones existentes desde tiempos remotos entre las poblaciones de la costa sur de Perú, norte de Chile actual y la zona alta andina han sido estudiados en forma intensiva durante los últimos años, a partir tanto de fuentes documentales como arqueológicas, etnológicas y lingüísticas. Parece muy probable que las interacciones costatierra alta, incluyendo la vertiente oriental de los Andes, hayan desempeñado un papel importante en el desarrollo de las culturas del Area Central y Centro Sur Andina. Existe, además, un cuerpo de documentación considerable que demuestra que estas vinculaciones continuaron en contextos coloniales. Sin embargo, lo que en este estudio nos interesa particularmente son las relaciones que puedan haberse efectuado en el sentido "longitudinal" u "horizontal"; vale decir, a lo largo de la costa. Es tema que ya ha sido abordado por varios autores (Rostworowski 1977a y b; Bittmann 1978, 1979; Shimada 1982), y se refiere a interacciones que seguramente deben haber variado tanto en el espacio como en el tiempo y que, por una parte, podrían haber formado parte integral del llamado sistema "vertical" o, quizás, haber funcionado en forma separada o independiente.

Nuestro interés es estudiar en este trabajo una parte de la población del litoral del Desierto de Atacama con el propósito de señalar cómo, durante la Colonia, se presenta una continuidad de vinculaciones entre ellas y las que ocuparon las franjas costeras, tanto hacia el sur como hacia el norte. Estas vinculaciones representarían un sistema de interrelaciones que debería tener raíces antiguas y que contendría características distintas de la tradición, basada en el control de los diversos pisos ecológicos de acuerdo al modelo llamado "verticalidad".

1 El presente estudio es parte del "Proyecto de Investigaciones Multidisciplinarias en la Costa Centro Sur Andina (Chile)", financiado por la Universidad del Norte.

2 Instituto de Investigaciones Arqueológicas R. P. Gustavo Le Paige s. j., Universidad del Norte, San Pedro de Atacama, CHILE.
En el presente estudio nos concentraremos, particularmente, en la situación de los "camanchacas", basándose especialmente en la información que proponen diversos documentos escritos, los que, hasta el momento, no han sido utilizados en el estudio de esta población.

\section{Antecedentes generales}

La costa sur de Perú se caracteriza por su extrema aridez. Este rasgo, sin embargo, se ve interrumpido por angostos valles, como los de Camaná, Majes, Tambo, Vítor, Siguas, Locumba, Moquegua, etc., y que incluyen a los valles de Lluta y Azapa en el norte de Chile. Esta franja costera, en su totalidad conforma una zona que, según testimonios coloniales, permitió, por una parte, el cultivo de diversos productos agrícolas (Bueno 1951; Alcedo 1967; Vázquez de Espinoza 1969) y, por otra, el aprovechamiento de la riqueza de los recursos del mar (Bueno 1951; Vázquez de Espinoza 1969). En la costa norte de Chile, entre Arica y Copiapó, se encuentra una zona costera aún más árida, situación que se agrava, particularmente, al sur de Pisagua, donde el único río que llega al mar es el Loa, quedando así una franja de más de $500 \mathrm{~km}$ de largo (hasta el río Copiapó) cuyas únicas fuentes de agua, relativamente dulce, las constituyen las llamadas "aguadas". En esta zona -situada a lo largo de la costa del Desierto de Atacama- desde época remota vivieron poblaciones, las que, prioritariamente, explotaron los recursos del mar, del litoral y de la cordillera cercana. Sin embargo, en cuanto a ellas, tambien existen evidencias tanto de la época prehispánica como colonial y posterior que señalan la importancia de interacciones de variada índole que se dieron con los pueblos que habitaron las distintas zonas ecológicas del interior (Bittmann 1977, 1979). Además, creemos importante insistir en la evidencia de distintos tipos que nos indica la existencia de vinculaciones, tanto económicas como sociales, los que al parecer se establecieron en el sentido horizontal o a lo largo de la costa (Bittmann 1978, 1979). 
Durante el tiempo de la colonización española los habitantes de la costa norte chilena aparecen en las fuentes escritas bajo distintos nombres: camanchacas, uros, pro-anches y changos. Como es sabido, muchos autores han debatido el significado de estas designaciones, ya que también había grupos humanos en el mismo litoral y en la misma época, los que no son mencionados con un nombre especial. El problema planteado, sin solución hasta nuestros días, se refiere fundamentalmente al significado de estas denominaciones -camanchaca, uro, pro-anche y chango-y sí indicarían, por ejemplo, alguna diferenciación étnica, social o, quizás, lingüística o física. Aparentemente, estas poblaciones compartieron un mismo tipo de economía basada, fundamentalmente, en la explotación de los recursos locales de la costa, los cuales como ya se ha indicado por una parte intercambiaron con productos de otros medios físicos del interior, mientras que, por otra, también hubo importantes interrelaciones entre los grupos que vivieron dispersos a lo largo del litoral.

A continuación se resumirá la información que se posee acerca del grupo llamado camanchacas.

\section{Los camanchacas: Costa norte de Chile y sur de Perú}

\section{Distribución}

La referencia más temprana que conocemos sobre los camanchacas proviene de un informe español (Relación 1889) que trata, entre otros aspectos, de las gestiones de los miembros de la expedición del corsario británico Sir Francis Drake en varios lugares a lo largo de la costa del Desierto de Atacama. A unas 11 leguas al norte "del puerto de Copiapó", los británicos, que anduvieron en búsqueda de agua potable, se encontraron en una isleta con cuatro "camanchacas". Posteriormente, según el mismo documento, en el Morro de Jorge, situado en la parte meridional de la península de Mejillones, tomaron contacto de nuevo con un camanchaca, que "vino en una balsa" y de quien los corsarios consiguieron pescado a cambio "de cuchillos y otras cosas".

Aun en el mismo siglo XVI, Lizárraga (1968: 50) escribió que a lo largo del litoral, entre el río Loa y Copiapó: “...hay algunas caletillas con poca agua salobre, donde se han recogido y huido algunos indios pescadores, pobres y casi desnudos; los vestidos son de pieles de lobos marinos y en muchas partes de la costa beben sangre de estos lobos a falta de agua; no alcanzan un grano de maíz ni lo tienen; su comida es sólo pescado y mariscos. Llaman a estos indios camanchacas, porque los rostros y cueros de sus cuerpos se les han vuelto como una costra colorada, durísima; dicen les proviene de la sangre que beben de los lobos marinos, y por ese color son conocidísimos."

Hay otras referencias a camanchacas, del siglo XVII, en el "Libro de varias ojas" (Casassas 1974), registro parroquial entre cuyas anotaciones correspondientes al período entre 1612 y 1661 aparecen individuos designados con este nombre. Según la información contenida en dicho "Libro", eran naturales de Cobija y Tocopilla, los que son claramente distinguidos de los habitantes de la misma zona denominados proanches o de los que no llevan designación especial alguna. Entre estos camanchacas, se menciona a una persona que lleva el apelativo "don", lo que indicaría que había alcanzado cierto nivel en la jerarquía establecida en la Colonia.

Otro documento sobre el área de distribución de los camanchacas y que, además, propone evidencia de que hubo algún tipo de diferenciación entre estos y los miembros de otro grupo llamado "changos", proviene de la ciudad de La Serena, donde fue emitido en 1659 (Bittmann 1977). Dicho documento hace referencia a indígenas encomendados en Fernando Aguirre Riberos cuya encomienda incluía a los indios del litoral situado entre Copiapó y Mejillones. En el documento se establece que ciertos "indios cananchacas y chiangos, pescadores y no pescadores... que estuvieran en Cobija y costa de Atacama..." habían huido hacia el norte de dicha encomienda. Otro aspecto interesante del contenido de este documento, es la información acerca de camanchacas como de changos con carácter de "pescadores y no pescadores" Cúneo Vidal (1977, I: 1450) también señala la presencia de camanchacas en la zona del litoral "comprendida entre Ilo y Tocopilla".

En cuanto a la distribución de los camanchacas, es interesante destacar que, en relación con la encomienda de Lucas Martínez Vegazo que se extendía desde Ilo y Moguegua hasta Tarapacá (Villalobos 1979: 22-33) y que fue traspasada durante un breve período a Jerónimo de Villegas. Cúneo Vidal (1977, 
5: 363-367) señala haber visto en el Archivo General de Indias de Sevilla un documento de 1550 relativo a este traspaso. Dicho expediente que se refiere a "la tasa de los tributos que los pueblos de los repartimientos de indios han de dar a sus encomendadores", señala (Cúneo Vidal 1977, 5: 365):

“...A vos, el capitán Hyerónimo de Villegas, vecino de la ciudad de Arequipa, e a vos Pedro que en vuestra lengua os llaman Choquechambi, chacyotapa (cacique) de los Uros sujetos y de los pescadores camanchacos que están en la costa, e los demás prencipales e indios uros sujetos, que al presente sois $y$ en adelante fuereis de la encomienda de vos..."

Por otro lado, aunque la provisión de Pizarro hecha en 1540, a Lucas Martínez Vegazo hace referencia al "señor Chaquichambi" (Villalobos 1979: 23); Cúneo Vidal 1977, 5: 363), esta concesión, aparentemente, no menciona a "los pescadores camanchacas" ni a los "indios uros sujetos".

Hay otra documentación que demuestra que los camanchacas habitaron la costa sur de Perú. Es así que en el Archivo Departamental de Arequipa se encuentra un documento emitido en 1639 (ADA 1639, fol. 18r), en el que se dice lo siguiente referente a la "Tassa de los yndios de Chule" (Chulín, cerca de Mejía):

"Los yndios camanchacas del puerto de Chule de la encomienda de Don Diego de Caseres digo de Vlloa pagan en cada año conforme a la tassa de Don Francisco de Toledo como parece y otra más moderna ciento y ochenta y siete pessos y cuatro reales de ocho el pesso que se distribuyen en la manera siguiente..."

El mismo documento (f. 49r) contiene otra referencia al "Cargo de los Yndios Camanchacas del puerto de Chule de la encomienda de Don Joseph de Caseres y Vlloa secretario de gobernación de estos rreynos." Entre dicho cargo había "treinta y seis arrobas de pescado en especie" que deberían ser cobradas en "los seis tersios de su cargo a rrazón cada año de dose arrobas...".

Las tasas de la visita general del virrey Francisco Toledo (1975: XXXI, 241-242), efectuada entre 1570 y 1575 , proponen información acerca de esta encomienda:

"El repartimiento de Pocosi [sic] con los indios de Cule [sic] y Tambo que es en los puertos de Arequipa tiene en encomienda en segunda vida Diego de Caceres hijo y sucesor del Capitán Alonso de Cazeres difunto a quien los encomendó el licenciado Pedro de la Gasca gobernador que fue de estos reinos."

En lo que corresponde a Chulín, el mismo documento señala lo siguiente:

"Y en los dichos indios de Chule y Tambo que tiene en encomienda el dicho Diego de Cazeres por una vida con el dicho repartimiento de Pocoi se hallaron en la visita general veinticinco indios de edad de tributar."

Estos indios pagaban cada año un tributo de 132 pesos de plata ensayada y marcada "los ciento veinte en plata y los doce en veinticuatro arrobas de pescado seco y salado de la mar a cuatro tominos el arroba".

El repartimiento de Potosí, así como los indios de la caleta de Chulín y el valle de Tambo, bajo la jurisdicción de Arequipa, fueron encomendados por el licenciado La Gasca hacia la mitad del siglo XVI en Alonso de Cáceres, militar español y gobernador de Arequipa, y a su muerte en 1554 le sucedió su hijo Diego (Zárate s/f: 661, 685, 708, 712, 843; Gobernantes del Perú, 1921-26, III: 450).

Del contenido de los documentos citados, se desprende que los camanchacas eran pescadores cuyo tributo incluía "pescado seco y salado". En tiempos de la visita de Toledo (1975: XXXI, 242), la población total de "Chule y Tambo" era de 120 personas.

Varios autores que escribieron en los primeros tiempos de la Colonia, señalan la ubicación geográfica de Chulín (Chule, Chuli, Chuly, Xulli). Entre ellos Cieza de León (s/f: 165), quien informa que era el puerto de la ciudad de Arequipa, situado en "diez y siete grados y medio largos", a 12 leguas al sur de Quilca y a dos leguas al norte del río Tampolla (Tambopalla). También Juan López de Velasco (1971: 248), con referencia a Arequipa, proporciona información sobre Chulín (ver también Hawkins s/f: 255):

"Pasa por junto a él un río bueno, que entra en la mar $17^{\circ}$, junto al cual está una caleta que llaman de Chule, del nombre del mismo río, diez y seis leguas de la ciudad, la cual sirve de puerto y se 
descargan en ella las mercaderías que se llevan de alli al Cusco, y las que se metían en la ciudad de la Plata y villa de Potosí antes que se descubriese el puerto de Arica..."

En otro lugar (Hawkins s/f: 250), el mismo autor dice que la "caleta de Chuly" está "cerca de donde se junta los distritos de las audiencias" (de los Reyes y Charcas).

En el "Mapa del Perú" confeccionado por Moll y publicado alrededor de 1660 se puede observar a la isla o isleta de "Xulli", situada al sur de Camaná y a poca distancia al norte del "Río de N. de Dios", en cual en un mapa posterior aparece bajo el nombre de "R. de Tambopalle i de nombre de Dios" (Figs. 1 y 2; ver también Alcedo 1967: 329).

Finalmente, respecto a los camanchacas, hay más documentación, la que proviene de la colección de manuscritos denominada Egerton que se encuentra depositada en la Biblioteca Británica, Londres. El nombre de Egerton se debe a que el $8^{\circ}$ Conde de Bridgewater, Francis Henry Egerton, en 1829 legó al Museo Británico tanto una importante colección de manuscritos como una suma considerable de dinero. Las rentas de este legado juntamente con las de otro fondo, llamado farnborough, se han utilizado y se utilizan hasta ahora para la compra de manuscritos, los que por este motivo conservan la designación de Egerton. Los documentos que nos interesan en este trabajo forman parte de una colección adquirida por el Museo Británico en un remate efectuado en Londres en 1859. De esta venta, provienen entre otros manuscritos la colección hecha por Martín Fernández Navarette (Egerton MSS, 1816) relativa a viajes tempranos hechos por los españoles a América y en el Pacífico Sur entre 1518 y 1621. Estos manuscritos, en su mayoría, consisten en transcripciones de copias de documentación existente en los archivos públicos de Sevilla. La colección, contiene, además, un borrador corregido de la "Noticia sumaria del viage que hicieron las corvetas de S.M.C. la Descubierta y Atrevida, del mando de Dn. Alexandro Malaspina, en los años de 1789 a 1794".

Entre los primeros documentos señalados de dicha colección se encuentran los dos relatos, ambos anónimos y de fecha desconocida, que proponen evidencia acerca del tema que nos ocupa aquí.

El primer manuscrito lleva el título Islas de Salomón (Egerton MSS, 1816, f. 223 r y v). La primera página, además del texto, tiene también una leyenda que dice.

"Relación muy particular dada al Capitán Francisco de Cáceres por un indio llamado Chepo y sería de edad de 115 á 120 años, de las islas de Salomón que están en la Mar del Sur, con expresión de sus nombres y el tiempo que tardaban los indios sus naturales desde el Puerto de Arica y de Ilo a ella..."

Esta relación se compone de preguntas que hizo Francisco Cáceres y las respuestas que dio el indio Chepo acerca de las características de las islas a donde llegaron los indígenas de Arica e Ilo después de una travesía de más de dos meses por mar, de los nombres de ellas (Coatu, Quen y Acabaña) y de sus señores (Quentique, Vquenique, Camanique, Acabana y Casira) y de las costumbres de sus habitantes. En lo que a los propósitos de este estudio se refiere, es de especial interés la pregunta de Cáceres acerca del idioma de estos isleños (f. 223v): "Preguntando que lenguaje tenían: dixo que sabía que entendían la lengua de D. Sebastián Camanchac (subrayado nuestro).

Sobre la base de esta información, es posible proponer las siguientes interpretaciones: 1) que Don Sebastián era miembro del grupo de camanchacas a cuya presencia en la costa del sur del Perú nos hemos referido anteriormente; 2) que el apelativo de "don", que él lleva, indica que era una persona "notable" o de rango reconocida como tal por los españoles y, 3) que, al menos en este caso, la designación de "camanchacas" debe corresponder a una clasificación lingüística.

\section{Evidencia lingüística}

No sabemos nada de la lengua de los camanchacas. La situación lingüística en la costa sur de Perú y del extremo norte de Chile, aparentemente, era compleja. A partir de la época del contacto con los europeos existen referencias a hablantes tanto del aymará, como del puquina, quechua, koli y uro, entre otros idiomas (Espinoza Soriano 1980 [1977] I: 111; Barriga 193955; Camacho 1943). En cuanto a la zona ubicada más al sur, en la costa del Desierto de Atacama, la evidencia también es conflictiva. Varios autores con referencia particular a los llamados "changos" han postulado que hablaron, por ejemplo, el araucano o que su lengua nativa pudo haber sido puquina o uro o "una mezcla de Atacama y aymara (Philippi 1856: 19; Bollaert 1860 I: 17; Bresson 1875: 892; Boman 
1908; Bird 1946; Medina 1952: 102-03; d'Ans 1976; Lehnert 1978; Espinoza Soriano 1980). Además, es interesante recordar la situación lingüística descrita por Lizárraga (1968: 13) referente a la población del valle de Chicama, Perú, en el siglo XVI, quien declara que: "Los indios deste valle tienen dos lenguas, que hablan: los pescadores una, y dificultosísima, y otra no tanto; pocas hablan la general del Inga...".

Es posible, también, que el uso de tal lengua "pescadora" o de una lingua franca pudiese haberse extendido entre las poblaciones del litoral que vivían al sur del valle de Chicama. Sea como fuese, la situación lingüística aborigen existente en la costa del Area Centro Sur Andina todavía constituye un problema que necesita ser aclarado.

Aunque no conocemos la fecha exacta del manuscrito de la Colección Egerton citada, parece probable que se trata de una de los varios relatos -recogidos en el siglo XVI por los europeos- de los indígenas que vivían a lo largo de la costa andina y que les inspiraron a realizar viajes de exploración en el Pacífico Sur. Es bien conocido que los españoles encontraron navegantes indígenas quienes con mucha destreza llevaron a efecto expediciones marítimas a grandes distancias a lo largo de la costa de Ecuador (Bittmann 1978). Por otro lado, también se recogieron tradiciones que trataron de expediciones realizadas mar adentro y del descubrimiento de islas cuya población y cuyas maravillas se describieron, tal como se desprende de los relatos proporcionados por Pedro Sarmiento de Gamboa (1940) y Cabello Balboa (1951), por ejemplo. Este tipo de datos, sin embargo, no sólo provienen de la costa andina situada al norte de la zona que en particular nos interesa en este estudio, sino también son proporcionados por Cieza de León (1977: 385) con referencia al descubrimiento de "unas islas grandes y ricas" ubicadas "por el paraje de Hacarí, bien adentro en la mar" y por el padre Acosta (1940: 53) quien señala que los indios de "Yca y los de Arica" antiguamente navegaban a unas islas situados hacia el poniente "muy lejos".

Parece entonces que de acuerdo a las tradiciones vigentes en la Colonia, desde la zona de los camanchacas de la costa meridional de Perú, se habrían efectuado viajes a larga distancia por vía marítima.

Además es interesante mencionar que en la Colección Egerton (f. 223 v.224r), se encuentra un relato titulado Otra Noticia que trata del descubrimiento de "una isla muy grande" situada en $18^{\circ}$ " a donde llegaron después de haber navegado durante noventa días "de la Gobernación de Chile". Este documento, sin embargo, no contiene referencia alguna a camanchacas.

\section{Consideraciones generales}

En cuanto a la posibilidad de que los indígenas de la costa andina hayan tenido contactos por vía marítima en tiempos precolombinos con los habitantes de islas situadas a larga distancia de la costa americana, es tema que ha sido debatido por varios autores, sobre evidencias de tipo documental, lingüística, etnológica y arqueológica como también sobre la base de la capacidad real de las embarcaciones de los indígenas tanto americanos como de las islas del Pacífico de afrontar los riesgos de un viaje a larga distancia mar adentro. Sin embargo, no es nuestra intención en este estudio tratar de discutir tal complejo problema, sino sólo hacer hincapié en los siguientes puntos respecto del uso del término "camanchaca":

1. Que dicho calificativo era aplicado en el Período Colonial a ciertos grupos de la población costera del área que en tiempos recientes se ha venido llamando Centro Sur Andina, los que, aparentemente, habitaron, por lo menos, la zona situada entre Copiapó por el sur y Chulín por el norte, aunque su distribución en dicha zona no fuese necesariamente continua.

2. Que en la parte septentrional de su área de distribución, los camanchacas constituyeron un grupo lingüístico.

Sobre la base de la evidencia disponible, parece que los camanchacas se dedicaron prioritariamente a la explotación de los recursos del mar y que se desplazaron a lo largo de la costa, aunque su punto de origen es, por el momento, desconocido. Es posible, tal como lo sugiere Lizárraga y el documento citado de La Serena, que representen grupos huidos a las caletas aisladas, tal vez por motivos de las exigencias de los españoles (ver también Cúneo Vidal 1977, 1: 483).

En cuanto a los camanchacas que habitaron la costa del Desierto de Atacama, Casassas (1974: 43) sobre la base de datos proporcionados por el "Libro de varias ojas", los ha caracterizado como marginales 
o, en otras palabras como "indios que no se habían incorporado en forma normal a la vida de los demás pobladores". Por otro lado, nosotros -basándonos en la misma evidencia pero utilizando el método demográfico de reconstitución de familias- hemos podido mostrar que estos camanchacas difícilmente pueden ser considerados como elementos "marginales", sino que, al contrario, habían establecido diversos tipos de vínculos de parentescos con otras poblaciones del litoral, tanto hacia el sur como hacia el norte.

En cuanto a la situación lingüística directamente relacionada con los camanchacas, poseemos solamente la evidencia de Chepo citada anteriormente.

Respecto del tipo físico de los camanchacas, lo señalado por Lizárraga sugiere alguna conexión directa entre el significado del término "camanchaca" y el aspecto colorado y duro de la piel de los individuos que así se designaban.

En lo que se refiere a los demás grupos habitantes de la costa norte de Chile, y que solamente hemos mencionado en forma muy somera en el presente estudio, según Latcham (1910), el territorio de los changos abarcaba la zona del litoral entre el río Loa por el norte y el río Choapa por el sur (ver también Niemeyer 1965-66). Bird (1946) opina que el área de ellos podría haber sido más extensa $\mathrm{y}$, asimismo, acepta a los changos como un grupo étnico independiente.

En cuanto a la situación prehistórica en tiempos cercanos a la llegada de los europeos, Bird (1946: 596) sostiene que el registro arqueológico demuestra la existencia de "diferencias culturales marcadas, con una difusión lenta de elementos culturales en dirección norte-sur", lo que corresponde estrechamente a lo dicho por Latcham en 1910. Asimismo, Bird (1946: 597) declara que la cultura de los changos, desde por lo menos Paposo hacia el sur, representaría una "mezcla de elementos extraídos de varias divisiones culturales que se evidencian en Arica y Punta Pichalo". Por otra parte, Willey (1971: 199) señala que "los changos del subárea de Atacama" representan no un grupo étnico independiente sino "los descendientes empobrecidos de los atacameños". Finalmente, Villalobos (1979: 24, Nota 7) -utilizando como base los datos proporcionados en la provisión de Francisco Pizarro a Lucas Martínez Vegazosostiene que "los llamados indios changos serían simplemente agrupaciones costeras de los indios del interior o aborígenes lugareños subordinados y mezclados con ellos". En cuanto a los llamados "uros marítimos", sobre los cuales también se ha especulado mucho, no tenemos en este momento ninguna evidencia nueva. En lo contingente a los pro-anches, la situación es similar, ya que solo sabemos de la existencia de ellos a través del "Libro de varias ojas" entre cuyas anotaciones correspondientes al período 1646 a 1662, aparece dicha designación asociada a personas naturales de Cobija, Morro Moreno, Copiapó y Puerto Loa.

En resumen, la información empírica de que se dispone no es suficiente para solucionar la problemática relativa a la situación étnica de los diversos pobladores, quienes en el momento del contacto europeo ocuparon el litoral del Area Centro Sur Andina, ni tampoco se tienen elementos antropológicos adecuados para identificar con seguridad los distintos grupos humanos de esta costa en el pasado precolombino tardío.

Creemos, sin embargo, que una investigación más amplia y multidisciplinaria que comprenda el estudio por especialistas de la totalidad de datos disponibles -arqueológicos, lingüísticos (sobre onomásticos, por ejemplo), etnohistóricos, etnográficos, antropo-físicos, demográficos, etc.podría ser de gran ayuda para llegar a una mejor comprensión, tanto de los problemas planteados en este estudio como de otros que se hayan presentado a los investigadores de los asuntos del pasado, concernientes a las poblaciones que ocuparon la costa del Desierto de Atacama. ${ }^{3}$

3 Es interesante destacar en relación con la situación lingüística que Jorge Hidalgo, en el mismo Subsimposio, hizo referencia a un documento de fines del siglo XVII, en el que se declara que los indígenas de Cobija hablaron un idioma distinto al de los habitantes del interior de la provincia. 


\section{REFERENCIAS CITADAS}

ADA. Archivo Departamental de Arequipa. Sección Histórica, Serie Corregimiento, Subserie Administración, 1639.

ALCEDO y HERRERA, A., 1967. Diccionario geográfico de las Indias Occidentales. Biblioteca de Autores Españoles, Editorial Atlas, Madrid.

AMHERST y B. THOMPSON, 1901. The discovery of Solomon Islands by Alvaro de Mendaña in 1568. Londres.

BARRIGA, V. M., 1939-55. Documentos para la historia de Arequipa, Editorial La Colmena, Arequipa.

BIRD, J., 1946. The historie inhabitants of the north chilean coast. Handbook of South American Indians, vol. 2, pp. 595-597. Washington D. C.

BITTMANN, B., 1977. Notas sobre poblaciones de la costa del Norte Grande chileno. En Aproximación a la etnohistoria del norte de Chile, J. M. Casassas (Ed.). Universidad del Norte, Antofagasta.

1978. Fishermen, Mummies and balsa rafts on the coast of Northern Chile. El Dorado 3 (3): 60-99.

_ 1979. Cobija y alrededores en la época colonial (16001750). Actas del VII Congreso de Arqueología Chilena vol. 2, pp. 327-356. Ediciones Kultrún, Santiago.

BOLLAERT, W., 1860. Antiquarian, ethnological and other researches in New Granada, Ecuador, Perú and Chile, with observations of the pre-incarial, incarial and other monuments of Peruvian nations. Trubner \& Co., Londres.

BOMAN, E., 1908. Antiquités de la région andine de la République Argentine et du Désert D’Atacama. Imprimerie Nationale, París.

BRESSON, A., 1875. Le Désert Atacama et Caracoles (Amérique $\mathrm{du} \mathrm{Sud})$. Le tour du monde. Nouveau journal des voyages, 29 (750-751): 371-532.

BUENO, C., 1951. Geografía del Perú virreinal (siglo XVIII). Lima.

CABELLO BALBOA, M., 1951. Miscelánea antártica: Una historia del Perú antiguo. Universidad Nacional Mayor de San Marcos, Instituto de Etnología, Lima.

CAMACHO, J. M., 1943. Urus, changos y atacamas. Boletín de la Sociedad Geográfica de La Paz 66: 9-35.

CASASSAS, J. M., 1974. La región atacameña en el siglo XVII. Datos históricos y socioeconómicos sobre una comarca de América meridional. Universidad del Norte, Antofagasta.

CIEZA DE LEON, P. DE, s/f. La crónica del Perú. En Crónicas de la conquista del Perú, pp. 125-497. Editorial Nueva España, México D. F.

1977. El señorío de los incas. Colección Autores Peruanos. Editorial Universo, Lima.
CUNEO VIDAL, R., 1977-1978. Obras completas. Ed. Ignacio Prado Pastor, Lima.

D’ANS, A. M. 1976. Chilueno o arauco, idioma de los changos del norte de Chile, dialecto mapuche septentrional. Estudios Atacameños 4: 124-130.

DEACOSTA, J. 1940. Historia natural y moral de las Indias. Fondo de Cultura Económica, México D. F., Buenos Aires.

EGERTON, 1816Ms. Navarrete, viages y descubrimientos: A collection by D. Martín Fernández de Navarrete of papers and tracts relative to the voyages of discovery of Magallanes and others to the South Sea..., British Museum, Londres.

ESPINOZA SORIANO, W., 1980. Los fundamentos lingüísticos de la etnohistoria andina y comentarios en torno al Anónimo de Charcas de 1604. Revista Española de Antropología Americana 10: 149-181.

GOBERNANTES DEL PERU, 1921-1926. Cartas y papeles siglo XVI. Documentos del Archivo de Indias. Publicación dirigida por D. R. Levillier, 14 vols. Sucesores de Rivadeneyra, Madrid.

HAWKINS, R., s/f. The observations of Sir Richard Hawkins, Knight in his voyage into the South Sea, anno domini 1593. En The Hawkins voyages during the reigns of Henry VIII, Queen Elizabeth and James I. Reprinted by Burt Franklin, Nueva York.

LATCHAM, R., 1910. ¿Quiénes eran los changos? Anales de la Universidad de Chile 126: 397-439.

LEHNERT R., 1978. Acerca de la lengua de los changos del norte de Chile, perspectiva bibliográfica. Cuadernos de Filosofía 8: 35-52.

LIZARRAGA, R. DE, 1968. Descripción breve de toda la tierra del Perú, Tucumán, río de la Plata y Chile. Biblioteca de Autores Españoles, Editorial Atlas, Madrid.

LOPEZ DE VELASCO, J., 1971. Geografía y descripción universal de las Indias. Biblioteca de Autores Españoles, vol. 205, Editorial Atlas, Madrid.

MEDINA, J. T., 1952. Los aborígenes de Chile. Fondo Histórico y Bibliográfico José Toribio Medina, Santiago.

NIEMEYER, H., 1965-66. Una balsa de cueros de lobo de la caleta de Chañaral de Aceitunas (Prov. de Atacama, Chile). Revista Universitaria L-LI, fasc. II. Anales de la Academia Chilena de Ciencias Naturales 28-29: 257-269.

PHILIPPI, R., 1856. Viaje al Desierto de Atacama, hecho de orden del Gobierno de Chile en el verano de 1853-54. Halle.

RELACION-1579, 1889. Relación de lo que el corsario Francisco hizo y robó en la costa de Chile y Perú, y las diligencias que el Virrey Don Francisco de Toledo hizo contra él. Colección Documentos Inéditos de la Historia de España, vol. p. 432, Madrid. 
ROSTWOROWSKI, M., 1977a. Mercaderes del valle de Chincha en la época prehispánica: Un documento y unos comentarios. En Etnia y Sociedad: Costa peruana prehispánica, pp. 97140. Instituto de Estudios Peruanos, Lima.

1977b. Pescadores, artesanos y mercaderes costeños en el Perú hispánico. En Etnia y Sociedad: Costa peruana prehispánica, pp. 211-271. Instituto de Estudios Peruanos, Lima.

SARMIENTO DE GAMBOA, P., 1940. Historia de los incas. Eusece Editores, Buenos Aires.

SHIMADA, IZUMI, 1982. Horizontal archipelago and coasthighland interaction in North Peru: Archaeological models. En El Hombre y su ambiente en los Andes Centrales, L. Millones y H. Tomoeda (Eds.), pp. 137-210. Senri Ethnological Studies 10. National Museum of Ethnology, Osaka.
TOLEDO, F. DE, 1975. Tasa de la visita general de Francisco Toledo. Universidad Nacional Mayor de San Marcos, Lima.

VAZQUEZ DE ESPINOSA, A., 1969. Compendio y descripción de las Indias Occidentales. Biblioteca de Autores Españoles, vol. 231, Madrid.

VILlalobOS, S., 1979. La economía de un desierto: Tarapacá durante la Colonia. Ediciones Nueva Universidad, Santiago.

WILLEY, G., 1971. An introduction to American archaeology, Prentice Hall, Englewood Cliffs, Nueva Jersey.

ZARATE, A. DE, Descubrimiento y Conquista del Perú. En Crónicas de la Conquista del Perú, pp. 500-893. Editorial Nueva España, México D. F. 